\title{
Evaluation of Knowledge, Attitudes and Practices of Malaria Among Forest-Goer Communities in Mukdahan Province, Northeastern Thailand
}

\section{Sriwipa Chuangchaiya}

Kasetsart University, Chalermphrakiat Sakon Nakhon Province Campus

Mohd Amirul Fitri A. Rahim

Faculty of Medicine, Universiti Kebangsaan Malaysia

\section{Paisit Chanpum}

Ban Koh Sub-ditrict Health Promoting Hospital

\section{Mohd Bakhtiar Munajat}

Universiti Kebangsaan Malaysia Faculty of Medicine: Hospital Canselor Tuanku Muhriz UKM

\section{Nor Diyana Dian}

Faculty of Medicine, Universiti Kebangsaan Malaysia

Inke Nadia D. Lubis

University of Sumatera Utara Faculty of Medicine: Universitas Sumatera Utara Fakultas Kedokteran

\section{Paul C. S. Divis}

Universiti Malaysia Sarawak Faculty of Medicine and Health Sciences

Zulkarnain Md Idris ( $\nabla$ zulkarnain.mdidris@ukm.edu.my)

Universiti Kebangsaan Malaysia https://orcid.org/0000-0002-4986-5393

\section{Research Article}

Keywords: Knowledge, attitude, and practice (KAP); Malaria; Mukdahan Province; Thailand

Posted Date: May 19th, 2021

DOI: https://doi.org/10.21203/rs.3.rs-516363/v1

License: (1) (1) This work is licensed under a Creative Commons Attribution 4.0 International License. Read Full License 


\section{Abstract}

Background: Malaria remains a major public health challenge in Thailand. In Thailand, the transmission now progressively clusters in hotspots along international borders and among high-risk groups, including forest-goers. Therefore, continuous assessment and understanding of the behavioral and perceptions related to malaria exposure in the high-risk group are necessary to achieve the elimination goal. This study aimed to investigate knowledge, attitudes and practices (KAP) related to malaria in rural communities living close to a forested area in the northeastern part of Thailand.

Methods: A community-based cross-sectional survey was conducted in three forest-goer communities (i.e. Ban Khok, Ban Koh and Dong Yang) in Khamcha-i district, Mukdahan Province from July and August 2019. Community members aged 18 years and above were interviewed. Demographic, socio-economic information and KAP data were collected using a structured questionnaire. Data were analyzed using descriptive statistics.

Results: Overall, 346 individuals were interviewed. Although the household indoor residual spraying (IRS) coverage was $100 \%$, ownership of mosquito bed net was $24.3 \%$ and only reported in Ban Khok. Nevertheless, almost all of the respondents were aware that malaria is transmitted by mosquitoes $(97.7 \%)$ and bed nets were used to prevent malaria (94.5\%). Regarding practice for managing malaria, the most common practice adopted by the respondents was seeking treatment at the nearby clinic (58.1\%), followed by self-healing (38.7\%) and self-purchase of medication from a local shop (3.2\%). Concerning attitude towards malaria transmission, $69.1 \%$ and $24.3 \%$ of the respondents reported entering nearby forests and spending the night in the forest within the last six months, respectively.

Conclusion: This study found that most respondents living in the villages have an acceptable level of knowledge and awareness about malaria. Nevertheless, the positive attitudes and practices concerning malaria prevention measures against malaria require marked improvement. Therefore, new approaches to improving malaria KAP evidently need in this community.

\section{Background}

Malaria is a vector-borne disease that is transmitted to humans by the infectious bites of female Anopheles mosquitoes. Globally, malaria is the top mosquito-borne disease that causes infection and death. In the WHO South-East Asia Region, approximately 200 million people in nine countries currently at high risk of infections with malaria [1]. Thailand, which is part of this region has made significant progress towards its goal of eliminating malaria by 2024 [2]. The country has continuously reduced its malaria burden over the last five years, the number of malaria cases has decreased by $84 \%$ from 34,611 in 2014 to 5425 in 2019 (Ministry of Public Health, 2019). However, this elimination effort still needs to be strengthened in the context of the surveillance system as a key intervention to accelerate the progress towards eradication target. 
In Thailand, malaria control efforts have been highly effective in alleviating infection across the country. Nonetheless, malaria is still endemic and a common disease in some areas of Thailand. The spread of malaria in Thailand is varying and can be characterized as 'forest malaria' and 'border malaria' with high transmission along international borders including Myanmar, Cambodia, Laos and Malaysia [3]. The distribution of malaria along these four international borders accounted for $69.5 \%$ of malaria cases and the western border with Myanmar has had the highest prevalence of malaria in Thailand [4]. Moreover, there has been a migration of migrant laborers from Myanmar to the Thai-Cambodian border provinces, mostly from high-transmission areas [5]. In a retrospective study in Thailand, the border regions of Thailand-Myanmar and Thailand-Cambodia, with high numbers of migrant workers, were found to have the highest incidence rates of malaria including Plasmodium falciparum, Plasmodium vivax and mixed infection [6]. A number of studies were also documented for naturally-acquired human infections with Plasmodium knowlesi in areas located near the border of Malaysia [7, 8, 9], thus portray the warning signs of an increasing $P$. knowlesi burden in Thailand.

Previous studies conducted in Thailand have shown that malaria is widespread among demographic groups engaged in certain high-risk behaviors $[10,11]$. In Northeast Thailand, the most vulnerable group to malaria include those living in remote areas as well as mobile and migrant populations [12]. These populations also live and work in areas with high malaria transmission and high human-vector contacts, such as forests and forest-fringe areas. These populations are mostly illiterate, deprived, and poorly connected with public health and surveillance programs, hospitals and legit pharmacists $[5,13]$. They are more likely to seek treatment from unregulated, private vendors who may raise their risk of exposure to non-standard and counterfeit medications or artemisinin-based monotherapies [14]. Their high mobility makes health promotion messages difficult to reach by the health authority and newcomers from nonendemic areas to endemic areas are at greater risk of infection because they have not been exposed to educational and prevention measures directed at endemic regions [11]. Therefore, it is crucial to inform the whole communities to continue or adopt preventive behaviors that can reduce the risk of infections.

This study aimed to evaluate the knowledge, attitudes and practices (KAP) regarding malaria among forest-goer communities living in rural areas in Mukdahan Province, one of the upper northeastern provinces of Thailand. To date, this is the first study on KAP regarding malaria conducted in this area. The KAP identified could be used as baseline data for future investigations regarding malaria prevention and control as well as for evaluating the effectiveness of strategies following implementation of malaria control programs.

\section{Methods}

\section{Ethics statement}

This study was approved by the Ministry of Health of Mukdahan Province, Thailand (ref. no.101.0032.2562) and the Medical Ethics Committee of the National University of Malaysia (ref. no. JEP-2019-148). Permission for fieldwork has also been received from the Regional Health Office and the 
District Health Office. Respondents were sensitized to the study objectives and procedures by the local health district personnel for the study participation. Written informed consent was obtained from all study participants and/or guardians before enrollment.

\section{Study Sites}

The study was conducted in three villages namely Ban Koh (latitude $16.5798^{\circ} \mathrm{N}$; longitude $102.4791^{\circ} \mathrm{E}$ ), Ban Khok (latitude $28.0024^{\circ} \mathrm{N}$; longitude $202.0825^{\circ} \mathrm{E}$ ) and Dong Yang (latitude $15.7539^{\circ} \mathrm{N}$; longitude 103.2721 ${ }^{\circ} \mathrm{E}$ ) located at the Khamcha-i district of Mukdahan Province, Northeastern Thailand (Fig. 1). These villages have been selected based on the recommendation from the local District Health Office, their representativeness of typical forest-fringe villages, availability of water bodies for breeding habitats of Anopheles mosquitoes and maintenance of the traditional activity of forest foraging where close contact with wild macaque are frequent. In 2013, 14 cases of malaria have been reported in Khamcha-i district including one fatality case due to vivax malaria (unpublished data, Department of Disease Control of Ministry of Health in Mukdahan Province).

Mukdahan Province is located in the northern region of the country (i.e. Isan Region). It had a population size of 342,200 in 2019 (Ministry of Interior, 2019). To the east, it borders the Mekong River, across which lies the Savannakhet Province of Laos. In the west of the province is the Phu Phan mountain range which is covered with thick dry dipterocarp and evergreen forests which includes several national parks and other protected areas. This mountain range is also home to two non-human primate populations namely the rhesus macaque (Macaca mulatta) and the pig-tailed macaque (Macaca nemesterina) [15]. The typical climate of the area is tropical with an average annual temperature of $27^{\circ} \mathrm{C}$ and average annual rainfall of $1,524 \mathrm{~mm}$. There is a short dry season between January and April, followed by a long wet season from May to December. While the main economic activity was based on agriculture, such as wetrice cultivation, the livelihoods of the villagers also relied on rubber-tapping and gathering and selling forest products.

\section{Study Design And Data Collection}

A cross-sectional survey was carried out between July and August 2019. All Thai nationals of both sexes, residing in the study villages and aged 18 and older were eligible. A convenience sampling strategy was used in this study, whereby residents were asked to come to selected survey points such as temples or clinics for study participation. Participants were explained about the study procedure and their consent was documented. Individuals who could not communicate or be unwilling to provide informed consent were excluded.

A standardized questionnaire was developed and administered to each participant to gather information concerning demographic, socio-economic, knowledge, attitudes and prevention practices on malaria. The questionnaire included a mixture of closed-ended and open-ended questions. A pre-tested and validated 
pilot survey was conducted at communities in other settings to evaluate the clarity, adequacy and comprehensibility of the questionnaire. In addition, preliminary interviews were also conducted to ensure standard interviewer's method and relevant interview questions were used. To minimize the courtesy bias and improve the accuracy of participants' self-reports, interviews were conducted by emphasizing anonymity by trained interviewers with on-site supervision. Before conducting the interviews, the lead researchers (SC and $\mathrm{ZMI}$ ) conducted a one-day training for the surveyors to explain each question in the questionnaire and how to conduct the interviews. The interview was conducted face-to-face using the Thai language and all questions were open-ended. A knowledge score was calculated according to correct answers.

\section{Statistical analysis}

The data collected were tabulated into a spreadsheet of Excel (Microsoft, USA) and cross-checked for errors. Data were processed and analyzed using Stata/SE version 13.1 for Windows (StataCorp, TX, USA). Data were presented as frequencies and percentages for categorical variables, while data for continuous variables were presented as the median and interquartile range (IQR). The variations between the characteristics of the respondents were analyzed using the Chi-squared, Fisher's exact or Kruskal-Wallis tests. $P$-values of $\leq 0.05$ were considered statistically significant.

\section{Results}

\section{Socio-demographic characteristics}

A total of 346 respondents in Mukdahan Province participated in this study (Table 1). Among these, $38.7 \%$ were inhabitants of Ban Khok, $21.7 \%$ of Ban Koh and $39.6 \%$ of Dong Yang rural areas. A slight majority of respondents were female (51.7\%) and gender distributions were similar across the three villages $(P=0.212)$. The median age of the respondents was 57 years (IQR: $47-64)$. More than half $(56.9 \%)$ of the respondents were in the age group of $31-60$ years $(P=0.395)$. The majority of the respondents were farmers (94.2\%), with a predominance of the respondents had a household monthly income of Thai Baht (THB) $\leq 8000$ ( US Dollar 260). With regard to the history of malaria, $74(21.4 \%)$ individuals reported contracting malaria for the past three months. 
Table 1

Sociodemographic characteristics of respondents in three forest-goer communities in Mukdahan Province, Northeastern Thailand in 2019.

\begin{tabular}{|c|c|c|c|c|c|}
\hline Characteristics & Overall & Ban Khok & Ban Koh & $\begin{array}{l}\text { Dong } \\
\text { Yang }\end{array}$ & $\begin{array}{l}P \\
\text { value }\end{array}$ \\
\hline Total number of respondents, $\mathrm{n}(\%)$ & $346(100)$ & $134(38.7)$ & $75(21.7)$ & $137(39.6)$ & \\
\hline \multicolumn{6}{|l|}{ Gender, n (\%) } \\
\hline Male & $167(48.3)$ & $71(53)$ & $38(50.7)$ & $58(42.3)$ & 0.212 \\
\hline Female & $179(51.7)$ & $63(47)$ & $37(49.3)$ & $79(57.7)$ & \\
\hline Age, median (IQR), years & $\begin{array}{l}57(47- \\
64)\end{array}$ & $\begin{array}{l}54(42- \\
62)\end{array}$ & $\begin{array}{l}57(48- \\
64)\end{array}$ & $\begin{array}{l}58(50- \\
65)\end{array}$ & 0.072 \\
\hline \multicolumn{6}{|l|}{ Age group, $\mathrm{n}(\%)$, years } \\
\hline $18-30$ & $31(9)$ & $15(11.2)$ & 8 (10.7) & $8(5.8)$ & 0.395 \\
\hline $31-60$ & $197(56.9)$ & $79(59)$ & $39(52)$ & $79(57.7)$ & \\
\hline$>60$ & $118(34.1)$ & $40(29.8)$ & $28(37.3)$ & $50(36.5)$ & \\
\hline \multicolumn{6}{|l|}{ Occupation, n (\%) } \\
\hline Farmer & $326(94.2)$ & $127(94.8)$ & $70(93.4)$ & $129(94.2)$ & 0.182 \\
\hline Student & $13(3.8)$ & $2(1.5)$ & $4(5.3)$ & $7(5.1)$ & \\
\hline Government & $7(2)$ & $5(3.7)$ & $1(1.3)$ & $1(0.7)$ & \\
\hline \multicolumn{6}{|l|}{ Income level ${ }^{\star}, \mathrm{n}(\%)$} \\
\hline$\leq$ THB 8000 & 304 (91.3) & $123(93.2)$ & $62(87.3)$ & $119(91.5)$ & 0.366 \\
\hline >THB 8001 & $29(8.7)$ & $9(6.8)$ & $9(12.7)$ & $11(8.5)$ & \\
\hline \multicolumn{6}{|l|}{$\begin{array}{l}\text { History of malaria in the last } 3 \\
\text { months }\end{array}$} \\
\hline No & $272(78.6)$ & $106(79.1)$ & $52(69.3)$ & $114(83.2)$ & 0.061 \\
\hline Yes & $74(21.4)$ & $28(20.9)$ & $23(30.7)$ & $23(16.8)$ & \\
\hline
\end{tabular}

\section{Knowledge, Attitudes And Practices Regarding Malaria By Area}

Generally, almost all respondents (97.7\%) were knowledgeable on the transmission of malaria via mosquito bites (Table 2). Approximately one-fifth of the respondents (20.8\%) believed that malaria can be 
transmitted by drinking water in the forest with the significantly highest respondents from Dong Yang ( $P$ $<0.001) .96 \%$ of the respondents recognized that fever, headache and chill as symptoms of malaria, with significant differences between study sites $(P<0.001)$. A small proportion of respondents $(3.8 \%)$ reported not taking any medication after contracting malaria. In contrast, respondents from Ban Khok reported the highest proportions of knowledge with regard to drug resistance due to incomplete adherence to the antimalarial drug $(97.8 \%, P<0.001)$, using bed net to prevent malaria $(100 \%, P<0.001)$ and the importance of malaria examination after returning from the forest (100\%), but lowest in the knowledge of relapsing fever due to malaria $(13.4 \%, P<0.001)$. 
Table 2

Knowledge, attitudes and practices (KAP) on malaria among respondents in three forest-goer communities in Mukdahan Province, Northeastern Thailand in 2019.

$\begin{array}{lclll}\text { Variables } & \text { Overall } & \begin{array}{l}\text { Ban } \\ \text { Khok }\end{array} & \begin{array}{l}\text { Ban } \\ \text { Koh }\end{array} & \begin{array}{c}\text { Dong } \\ \text { Yang }\end{array} \\ & & P \\ \text { value }\end{array}$

\section{Knowledge about malaria}

Do you know that malaria caused by mosquito bites?, n (\%)

$\begin{array}{llllll}\text { No } & 8(2.3) & 6 & 1 & 1 & 0.099 \\ & & (4.5) & (1.3) & (0.7) & \\ \text { Yes } & 338 & 128 & 74 & 136 & \\ & (97.7) & (95.5) & (98.7) & (99.3) & \end{array}$

Do you know that malaria can cause fever, headache and chill?, n (\%)

$\begin{array}{llllll}\text { No } & 15 & 2 & 12 & 1 & < \\ & (4.3) & (1.5) & (16) & (0.7) & 0.001^{*} \\ \text { Yes } & & & & & \\ & & & & & \\ & (95.7) & (98.5) & (84) & (99.3) & \end{array}$

If you get infected with malaria, do you take any medication?, n (\%)

$\begin{array}{llllll}\text { No } & 13 & 1 & 4 & 8 & 0.063 \\ \text { Yes } & (3.8) & (0.8) & (5.3) & (5.8) & \\ & 333 & 133 & 71 & 129 & \\ & (96.2) & (99.2) & (94.7) & (94.2) & \end{array}$

Do you think if you drink water from the forest you can easily get infected by malaria?, $\mathrm{n}(\%)$

\begin{tabular}{|llllll|} 
No & 274 & 125 & 57 & 92 & $<$ \\
Yes & $(79.2)$ & $(93.3)$ & $(76)$ & $(67.2)$ & $0.001^{*}$ \\
& 72 & 9 & 18 & 45 & \\
& $(20.8)$ & $(6.7)$ & $(24)$ & $(32.8)$ & \\
$\begin{array}{l}\text { Do you know you can develop drug resistance if you } \\
\text { are not complete the antimalarial drug?, n (\%) }\end{array}$ & & & & & \\
No & 35 & 3 & $3(4)$ & 29 & \\
& $(10.1)$ & $(2.2)$ & & $(21.2)$ & $0.001^{*}$ \\
Yes & 311 & 131 & 72 & 108 & \\
& $(89.9)$ & $(97.8)$ & $(96)$ & $(78.8)$ & \\
\hline
\end{tabular}

*Significant difference $P<0.05 ;{ }^{\dagger}$ Among those who own bed net $(\mathrm{n}=84)$; IRS = Indoor residual spraying 


$\begin{array}{lll}\text { Ban } & \text { Dong } & P \\ \text { Koh } & \text { Yang } & \text { value }\end{array}$

Do you know the use of a bed net can prevent malaria infection?, n (\%)

$\begin{array}{llllll}\text { No } & 19 & 0(0) & 5 & 14 & 0.001^{*} \\ \text { Yes } & (5.5) & & (6.7) & (10.2) & \\ & 327 & 134 & 70 & 123 & \\ & (94.5) & (100) & (93.3) & (89.8)\end{array}$

Do you think you need to examine yourself from malaria after coming back from the forest?, n (\%)

$\begin{array}{lllll}\text { No } & 3(0.9) & 0(0) & 3(4) & 0(0) \\ \text { Yes } & 343 & 134 & 72 & 137 \\ & (99.1) & (100) & (96) & \end{array}$

Do you think if you get infected with malaria, you may have a relapsing fever later?, n (\%)

\begin{tabular}{lllllll} 
No & 216 & 116 & 1 & 99 & $<$ \\
& $(62.4)$ & $(86.6)$ & $(1.3)$ & $(72.3)$ & $0.001^{*}$ \\
\hline Yes & & & & & \\
& 130 & 18 & 74 & 38 & \\
& $(37.6)$ & $(13.4)$ & $(98.7)$ & $(27.7)$ &
\end{tabular}

\section{Attitude towards malaria transmission}

Live within $500 \mathrm{~m}$ from the forest, $\mathrm{n}$ (\%)

$\begin{array}{llllll}\text { No } & 93 & 25 & 27 & 41 & 0.015^{*} \\ \text { Yes } & (26.9) & (18.7) & (36) & (29.9) & \\ & 253 & 109 & 48 & 96 & \\ & (73.1) & (81.3) & (64) & (70.1)\end{array}$

Spending the night in the forest within the last 6 months, $\mathrm{n}(\%)$

$\begin{array}{llllll}\text { No } & 262 & 113 & 54 & 95 & 0.011^{*} \\ \text { Yes } & (75.7) & (84.3) & (72) & (69.3) & \\ & & 84 & 21 & 21 & 42 \\ & (24.3) & (15.7) & (28) & (30.7) & \end{array}$

Visited the nearby forest within the last 6 months, $\mathrm{n}$ (\%)

No

$\begin{array}{lllll}107 & 38 & 26 & 43 & 0.632 \\ (30.9) & (28.4) & (34.7) & (31.4) & \end{array}$

*Significant difference $P<0.05 ;{ }^{\dagger}$ Among those who own bed net $(\mathrm{n}=84)$; IRS = Indoor residual spraying 


\begin{tabular}{|c|c|c|c|c|c|}
\hline Variables & Overall & $\begin{array}{l}\text { Ban } \\
\text { Khok }\end{array}$ & $\begin{array}{l}\text { Ban } \\
\text { Koh }\end{array}$ & $\begin{array}{l}\text { Dong } \\
\text { Yang }\end{array}$ & $\begin{array}{l}P \\
\text { value }\end{array}$ \\
\hline Yes & $\begin{array}{l}239 \\
(69.1)\end{array}$ & $\begin{array}{l}96 \\
(71.6)\end{array}$ & $\begin{array}{l}49 \\
(65.3)\end{array}$ & $\begin{array}{l}94 \\
(68.6)\end{array}$ & \\
\hline \multicolumn{6}{|l|}{ Practice to prevent the spread of malaria } \\
\hline \multicolumn{6}{|l|}{ Bed net ownership, n (\%) } \\
\hline No & $\begin{array}{l}262 \\
(75.7)\end{array}$ & $\begin{array}{l}50 \\
(37.3)\end{array}$ & $\begin{array}{l}75 \\
(100)\end{array}$ & $\begin{array}{l}137 \\
(100)\end{array}$ & - \\
\hline Yes & $\begin{array}{l}84 \\
(24.3)\end{array}$ & $\begin{array}{l}84 \\
(62.7)\end{array}$ & $0(0)$ & $0(0)$ & \\
\hline \multicolumn{6}{|l|}{ Sleep under a bed net ${ }^{\dagger}, \mathrm{n}(\%)$} \\
\hline No & $0(0)$ & $0(0)$ & $0(0)$ & $0(0)$ & - \\
\hline Yes & $\begin{array}{l}84 \\
(100)\end{array}$ & $\begin{array}{l}84 \\
(100)\end{array}$ & $0(0)$ & $0(0)$ & \\
\hline \multicolumn{6}{|l|}{ IRS within the last 12 months, $\mathrm{n}(\%)$} \\
\hline No & $0(0)$ & $0(0)$ & $0(0)$ & $0(0)$ & - \\
\hline Yes & $\begin{array}{l}346 \\
(100)\end{array}$ & $\begin{array}{l}134 \\
(100)\end{array}$ & $\begin{array}{l}75 \\
(100)\end{array}$ & $\begin{array}{l}137 \\
(100)\end{array}$ & \\
\hline \multicolumn{6}{|l|}{ The practice of managing the illness, $\mathrm{n}(\%)$} \\
\hline Go to the nearby clinic immediately & $\begin{array}{l}201 \\
(58.1)\end{array}$ & $4(3)$ & $\begin{array}{l}74 \\
(98.7)\end{array}$ & $\begin{array}{l}123 \\
(89.8)\end{array}$ & $\begin{array}{l}< \\
0.001^{*}\end{array}$ \\
\hline Wait out the symptoms until well & $\begin{array}{l}134 \\
(38.7)\end{array}$ & $\begin{array}{l}125 \\
(93.3)\end{array}$ & $\begin{array}{l}1 \\
(1.3)\end{array}$ & $\begin{array}{l}8 \\
(5.8)\end{array}$ & $<.001^{*}$ \\
\hline Purchase medication from the local shop & $\begin{array}{l}11 \\
(3.2)\end{array}$ & $\begin{array}{l}5 \\
(3.7)\end{array}$ & $0(0)$ & $\begin{array}{l}6 \\
(4.4)\end{array}$ & 0.198 \\
\hline $\begin{array}{l}{ }^{*} \text { Significant difference } P<0.05 ;{ }^{\dagger} \text { Among th } \\
\text { spraying }\end{array}$ & bed net & = 84); & $=\operatorname{lnd}$ & residual & \\
\hline
\end{tabular}

With respect to attitudes, most respondents (73.1\%) with significant predominance from Ban Khok (81.3\%, $P=0.015)$ reported live within $500 \mathrm{~m}$ from the forest. Although the villagers live near a forested area, respondents from Don Yang $(30.7 \%, P=0.011)$ and Ban Khok $(71.6 \%)$ reported the highest proportions of spending the night and entered the forest for the past six months, respectively.

Most respondents (75.7\%) did not own bed nets as part of practicing on preventing the spread of malaria, however, only respondents in Ban Khok responded well to this practice (62.7\% of 134 respondents). Nevertheless, there was remarkable compliance for nightly usage of bed net among those who own the bed net (100\%). Similarly, all respondents reported $100 \%$ coverage of indoor residual spraying (IRS) by the 
health authority at least once during 2019. Moreover, approximately $60 \%$ of the respondents reported seeking immediate treatment at the nearby clinic with significantly higher respondents from Ban Koh than the other villages $(P<0.001)$. In contrast, respondents from Ban Khok claimed the highest proportion of wait out the symptoms until well $(93.3 \%, P<0.001)$. Only a small proportion was still considered buying medication directly from the local shop (3.2\%).

\section{Knowledge, Attitudes And Practices Regarding Malaria By Age Group}

Table 3 shows the association between the respondents' knowledge, attitudes and practice about malaria stratified by their age groups. Albeit not significant, the results showed high levels of knowledge among all age groups concerning the cause of malaria (96.5-100\%), malaria symptoms (95.4-96.8\%), the importance of malaria treatment (93.6-96.6\%) and the potential of drug resistance (88.1-93.6\%), the benefit of mosquito bed net (92.4-100\%) as well as the importance of malaria examination after returning from the forest (98.9-100\%). Furthermore, respondents in the $>60$ group had the highest proportion (22.9\%) in believed that malaria can be transmitted by drinking water in the forest. Meanwhile, respondents in the 18-30 had higher levels of knowledge of relapsing fever due to malaria $(51.6 \%)$ than the older age groups. 
Table 3

Knowledge, attitudes and practices (KAP) on malaria among different age groups of the forest-goer community in Mukdahan Province, Northeastern Thailand in 2019.

$\begin{array}{lllll}\text { Responded affirmatively } & 18- & 31- & >60 & P \\ & 30 & 60 & & \text { value }\end{array}$

\section{Knowledge about malaria}

Do you know that malaria caused by mosquitoe bites? - Yes, $n$ $(\%)$

$\begin{array}{llll}31 & 190 & 117 & 0.202 \\ (100) & (96.5) & (99.2) & \end{array}$

Do you know that malaria can cause fever, headache and chill?

- Yes, n (\%)

$\begin{array}{llll}30 & 188 & 113 & 0.942\end{array}$

If you get infected with malaria, do you take any medication? Yes, $\mathrm{n}(\%)$

(96.8) (95.4) (95.8)

$\begin{array}{llll}29 & 190 & 114 & 0.709\end{array}$

(93.6) (96.5) (96.6)

Do you think if you drink water from the forest you can easily get infected by malaria? - Yes, n (\%)

$\begin{array}{lll}5 & 40 & 27 \\ (16.1) & (20.3) & (22.9)\end{array}$

Do you know you can develop drug resistance if you are not complete the antimalarial drug? -

$\begin{array}{lll}29 & 178 & 104 \\ (93.6) & (90.4) & (88.1)\end{array}$

0.687

Yes, n (\%)

Do you know the use of a bed net can prevent malaria infection? - Yes, $\mathrm{n}(\%)$

\begin{tabular}{llll}
31 & 187 & 109 & 0.234 \\
$(100)$ & $(94.9)$ & $(92.4)$ & \\
31 & 195 & $\begin{array}{l}117 \\
(100)\end{array}$ & 0.851 \\
$(98.9)$ & $(99.2)$ & \\
16 & 70 & 44 & 0.229 \\
$(51.6)$ & $(35.5)$ & $(37.3)$ & \\
\hline
\end{tabular}

Do you think you need to examine yourself from malaria after coming back from the forest? -Yes, $\mathrm{n}(\%)$

Do you think that if you get infected with malaria, you may have a relapsing fever later? - Yes, $n(\%)$

0.637

\section{Attitude towards malaria transmission}

Live within $500 \mathrm{~m}$ from the forest - Yes, $\mathrm{n}(\%)$

$\begin{array}{llll}22 & 140 & 91 & 0.483 \\ (70.9) & (71.1) & (77.1) & \end{array}$

Spending the night within $500 \mathrm{~m}$ from the forest fringe or

within the forest - Yes, $n(\%)$

$\begin{array}{llll}9 & 53 & 22 & 0.206\end{array}$

Visited the nearby forest within the last 6 months - Yes, $n(\%)$

$\begin{array}{llll}18 & 151 & 70 & 0.002 * \\ (58.1) & (76.7) & (59.3) & \end{array}$

\section{Practice to prevent the spread of malaria}

Bed net ownership -Yes, n (\%)

$\begin{array}{lll}10 & 48 & 26 \\ (32.3) & (24.4) & (22)\end{array}$

The practice of managing illness

Go to the nearby clinic immediately - Yes, $n$ (\%)

$\begin{array}{lll}17 & 113 & 71 \\ (54.8) & (57.4) & (60.2)\end{array}$

0.846 


\begin{tabular}{|lllll|}
\hline Responded affirmatively & $\mathbf{1 8 -}$ & $\mathbf{3 1 -}$ & $>\mathbf{6 0}$ & $\boldsymbol{P}$ \\
\hline Wait out the symptoms until well - Yes, $\mathrm{n}(\%)$ & $\mathbf{3 0}$ & $\mathbf{6 0}$ & & value \\
\hline Purchase medication from local shop - Yes, $\mathrm{n}(\%)$ & 13 & 79 & 42 & 0.846 \\
& $(41.9)$ & $(40.1)$ & $(35.6)$ & \\
\hline "Significant difference $P<0.05$ & 1 & 5 & 5 & 0.588 \\
\hline
\end{tabular}

The proportions of attitudes regarding malaria were varied by age group. Albeit not significant, the proportions were highest in the $>60$ group that live within $500 \mathrm{~m}$ from the forest $(77.1 \%)$ and in the 18 30 group that reported spending a night in the forest for the past six months (29.1\%). Interestingly, the proportion of respondents who reported entered the forest for the past six months was significantly higher $(76.7 \%, P=0.002)$ in the 31-60 group compared to other age groups. In terms of practice on preventing the spread of malaria, no significant differences were observed between age groups concerning the practice to prevent the spread of malaria.

\section{Discussion}

Understanding the perceptions of malaria among forest-goers is crucial as there are priority populations for malaria elimination particularly in the Greater Mekong Subregion (GMS) [16]. This study is the first to offer insight into the level of knowledge, attitude and practices toward malaria among forest-goer communities living in rural areas in Mukdahan Province, Thailand. This group of individuals has previously been associated with a greater risk of sub-clinical malaria infections [17] and with the suboptimal use of malaria preventive interventions [18]. Also, it is increasingly recognized that forest-goers are at particular risk of zoonotic malaria because they are highly likely to come into close contact with macaques and other monkey species during their activities in the forest that potentially carrying nonhuman Plasmodium species [19, 20].

In this study, knowledge of malaria transmission was high among forest-goers in Mukdahan Province. Almost all of the respondents ( $98 \%$ ) acknowledge that mosquito bite transmits the malaria parasite to humans, and this could be explained by the $100 \%$ bed net use during the night by the respondents that owned the bed net. A comprehensive systematic review by Nofal et al reported that forest-goer respondents in GMS countries including Thailand often described that mosquito bites were the cause of malaria [18]. Nevertheless, a misconception regarding the mode of transmission was also reported in the present study. About one-fifth of our respondents believed that drinking unclean water could also transmit malaria. In GMS countries, this misconception is common. Malaria was also linked to bathing in contaminated water, exposure to contaminated wind, tiredness, poor hygiene and even eating specific dishes [18]. In addition, supernatural deities and forest spirits were also reported as causes of malaria among forest-goers in Cambodia [21, 22, 23]. 
Local variation in attitude towards malaria transmission was also observed among communities in the province. This study found that almost a quarter of the respondents spent the night in the forest within the last six months of the survey, but the range varied significantly between settings (i.e.16-31\%). A study in Cambodia showed that the forest-goer spends at most one week per month in the forest and the risk for malaria infection was varied among different forest-goer communities [24]. Furthermore, this study also found significantly higher respondents from the age of 31 to 60 years have frequently visited the forest. As a working-age population, they are likely responsible for the family economy to gain additional income from traditional farming or their primary livelihood activity [18, 24, 25]. In addition, some foresters intend to stay longer in the forest to increase their earnings, especially during harvesting periods [26]. This behavior will increase the risk of malaria among forest-goers. Therefore, a comprehensive epidemiological study is needed to better understand the risk factors associated with seasonal exposure and time spent in the forest in this community.

Prevention of malaria by bed net application within the communities had been recorded in this study with a varying degree of conformity. Concerning practice on preventing the spread of malaria, a low number of overall ownership of mosquito bed net (24\%) was reported in the communities and surprisingly reported from only one village (i.e. Ban Khok, 63\%). Low bed net coverage by the health authority and nonadherence to the use of bed nets from the communities are critical failures to the local malaria control program. The local health authority needs to address this situation by engaging the community directly through education and awareness programs on the importance of mosquito bed net. Indeed, the application and full coverage of long-lasting insecticidal nets (LLINs)/insecticide-treated bed nets (ITNs) are some of the effective methods for malaria prevention and control [27]. Accordingly, the Ministry of Public Health of Thailand has specified to distribute LLIN or ITNs with a target of one bed net per twoperson in active foci areas of the country [28].

Nearly $42 \%$ of respondents in this study do not go to the clinic or health facilities when they experience malaria-like symptoms. This may be due to the remote location of the villages, causing difficulty for villagers in obtaining health assistance. Apart from that, the difficulty of getting public transportation or vehicles is also one of the factors that contribute to the low percentage of those who seek medical treatment in health facilities. The long distances between villager's houses and local health facilities have been described as a factor the community reluctant to seek treatment for malaria in Myanmar [29]. Furthermore, most of the respondents in the current study who do not seek medical attention are from the age group of over 30 years old. This is most probably because they only rely on and believe in traditional healers or self-medication practices when they are contracted with malaria. A previous study conducted in the Thailand-Myanmar border of Tak Province showed that the majority of respondents initially attempted self-treatment and few of them visited a traditional healer once they had malaria symptoms [30]. In addition, some respondents may think that the cost of diagnosis and treatment of malaria is expensive, so they choose to only buy medicine at the store, without consulting qualified health care personnel. To encourage the villagers to seek medical treatment in health facilities, self-awareness toward symptoms of malaria needs to be increased. Besides that, government and non-government 
sectors should put their efforts to provide essential health care personnel covering all villages especially those in remote and endemic areas.

This finding had limitations. First, while the convenient sampling approach used in this study was efficient and cost-effective, it has inherent selection bias. The survey was conducted mostly during the weekdays, meaning that younger adults were disproportionally represented. This group of individuals typically away from home during weekdays in the study area. Under-representation of this age group may likely underestimate the true data in the study areas. Second, the cross-sectional study design can only provide information about a certain point in time and the response of participants may not the same in different seasons. Thus, it is unable to determine rates of change or stochastic variation. Third, the validity of the information provided by respondents in the absence of independent checks or attempts to minimize errors of recall. These kinds of research limitations are difficult to avoid in areas where funding is often largely inadequate. Fourth, the assessment was based on a questionnaire therefore the actual behavior of the participants could not be represented in the reality.

\section{Conclusions}

In summary, most of the respondents had an acceptable level of knowledge and awareness about malaria. However, only some indicated that they would seek treatment quickly if symptoms develop. Furthermore, the attitudes and practices in relation to malaria prevention including spending the night in the forest and bed net coverage among forest-goers still need improvement. Thus, it is recommended that a set of local strategies should be formulated to increase knowledge about malaria and to promote positive attitudes and wide coverage on the implementation of prevention and control measures aimed at minimizing the exposure among forest-goer communities in the area.

\section{Abbreviations}

IQR: Interquartile range; IRS: Indoor residual spraying; KAP: Knowledge, attitude and practice; THB: Thai baht; USD: United State dollar; WHO: World Health Organization.

\section{Declarations}

\section{Acknowledgments}

We would like to extend our gratitude to the communities and community leaders for their support and participation in the survey. We wish to sincerely thank all members of the field team. We are grateful to the director of the Khamcha-i District Public Health Office and the director of Sub-District Health Promoting Hospital at Ban Koh for their support throughout the study. We are grateful to Laun Palawong, Panuwat Kantee, Thiti Srihanam, Sudarat Chaisangrat and Sujitrapa Surasan for their assistance in the survey. 
ZMI, SC, PCSD and INDL conceived and designed the study. SC, MAFAR, PC and ZMI performed the fieldwork. SC, MAFAR, MBM and NDD performed data cleaning and analyzed the data. SC, MAFAR, MBM, NDD, PCDS and ZMI interpreted the data. SC, MAFAR, MBM and NDD wrote the first draft of the manuscript. PCSD and ZMI provided critical revision of the manuscript for important intellectual content. All authors read and approved the final manuscript.

\section{Funding}

This work (PI: ZMI) was supported by the ASEAN Science Technology and Innovation Fund (ASTIF; FF2019-124) from the ASEAN Secretariat. MAFAR was supported by the Geran Pembiayaan Sepadan (FF2019-124/1) from the Faculty of Medicine, Universiti Kebangsaan Malaysia. MBM was supported by the Hadiah Latihan Persekutuan (HLP) administrated by the Ministry of Health, Malaysia.

\section{Ethics approval and consent to participate}

This study was approved by the Ministry of Health of Mukdahan Province, Thailand (ref. no.101.0032.2562) and the Medical Ethics Committee of the National University of Malaysia (ref. no. JEP-2019-148). Permission for fieldwork has also been received from the Regional Health Office and the District Health Office. Written informed consent was obtained from all participants in this study.

\section{Availability of data and materials}

The dataset used and/or analyzed during the current study are available from the corresponding author upon request.

\section{Consent for Publication}

All authors approved the final draft for journal submission.

\section{Conflict of Interest}

The authors declare no competing financial interests.

\section{References}

1. WHO. World Malaria Report 2020. Geneva: World Health Organization. 2020. https://www.who.int/publications/i/item/9789241565721.

2. WHO. Progress towards 0. Malaria-Free in SEAR 2010-2018. Regional Office for South-East Asia. 2020. https://apps.who.int/iris/handle/10665/334208.

3. Sattabongkot J, Suansomjit C, Nguitragool W, Sirichaisinthop J, Warit S, Tiensuwan M, et al. Prevalence of asymptomatic Plasmodium infections with sub-microscopic parasite densities in the northwestern border of Thailand: a potential threat to malaria elimination. Malar J. 2018;17:329. 
4. Sriwichai P, Karl S, Samung Y, Kiattibutr K, Sirichaisinthop J, Mueller I, et al. Imported Plasmodium falciparum and locally transmitted Plasmodium vivax. cross-border malaria transmission scenario in northwestern Thailand. Malar J. 2017;16:258.

5. Parker DM, Carrara VI, Pukrittayakamee S, McGready R, Nosten FH. Malaria ecology along the Thailand-Myanmar border. Malar J. 2015;14:388.

6. Imwong M, Nguyen TN, Tripura R, Peto TJ, Lee SJ, Lwin KM, et al. The epidemiology of subclinical malaria infections in South-East Asia: findings from cross-sectional surveys in Thailand-Myanmar border areas, Cambodia, and Vietnam. Malar J. 2015;14:381.

7. Jongwutiwes S, Buppan P, Kosuvin R, Seethamchai S, Pattanawong U, Sirichaisinthop J, et al. Plasmodium knowlesi malaria in humans and macaques, Thailand. Emerg Infect Dis. 2011;17:1799.

8. Ngernna S, Rachaphaew N, Thammapalo S, Prikchoo P, Kaewnah O, Manopwisedjaroen K, et al. Case report: Case series of human Plasmodium knowlesi infection on the Southern border of Thailand. Am J Trop Med Hyg. 2019;101:1397-401.

9. Putaporntip C, Hongsrimuang T, Seethamchai S, Kobasa T, Limkittikul K, Cui L, et al. Differential prevalence of Plasmodium infections and cryptic Plasmodium knowlesi malaria in humans in Thailand. J Infect Dis. 2009;199:1143-50.

10. Cotter C, Sturrock HJ, Hsiang MS, Liu J, Phillips AA, Hwang J, et al. The changing epidemiology of malaria elimination: new strategies for new challenges. The Lancet. 2013;382:900-11.

11. Ly P, Thwing J, McGinn C, Quintero CE, Top-Samphor N, Habib N, et al. The use of respondent-driven sampling to assess malaria knowledge, treatment-seeking behaviours and preventive practices among mobile and migrant populations in a setting of artemisinin resistance in Western Cambodia. Malar J. 2017;16:1-9.

12. Delacollette C, D'Souza C, Christophel E, Thimasarn K, Abdur R, Bell D, et al. Malaria trends and challenges in the Greater Mekong Subregion. Southeast Asian J Trop Med Public Health. 2009;40:674.

13. Munajat MB, Rahim MAFA, Wahid W, Seri Rakna MIM, Divis PCS, Chuangchaiya S, et al. Perceptions and prevention practices on malaria among the indigenous Orang Asli community in Kelantan, Peninsular Malaysia. Malar J. 2021;20:202.

14. Yeung S, Van Damme W, Socheat D, White NJ, Mills A. Access to artemisinin combination therapy for malaria in remote areas of Cambodia. Malar J. 2008;7:96.

15. Srokosamatra S, Doungkhae S. Dry dipterocarp forest as a barrier to gibbon dispersal: a survey in Phu Phan National Park, Northeast Thailand. Nat Hist Bull Siam Soc. 1982;30:25-32.

16. Guyant P, Canavati SE, Chea N, Ly P, Whittaker MA, Roca-Feltrer A, et al. Malaria and the mobile and migrant population in Cambodia: a population movement framework to inform strategies for malaria control and elimination. Malar J. 2015;14:1-15.

17. Parker DM, Tripura R, Peto TJ, Maude RJ, Nguon C, Chalk J, et al. A multi-level spatial analysis of clinical malaria and subclinical Plasmodium infections in Pailin Province, Cambodia. Heliyon. 2017;3:e00447. 
18. Nofal SD, Peto TJ, Adhikari B, Tripura R, Callery J, Bui TM, et al. How can interventions that target forest-goers be tailored to accelerate malaria elimination in the Greater Mekong Subregion? A systematic review of the qualitative literature. Malar J. 2019;18:32.

19. Imwong M, Madmanee W, Suwannasin K, Kunasol C, Peto TJ, Tripura R, et al. Asymptomatic natural human infections with the simian malaria parasites Plasmodium cynomolgi and Plasmodium knowlesi. J Infect Dis. 2019;219:695-702.

20. Moyes CL, Shearer FM, Huang Z, Wiebe A, Gibson HS, Nijman V, et al. Predicting the geographical distributions of the macaque hosts and mosquito vectors of Plasmodium knowlesi malaria in forested and non-forested areas. Parasit Vectors. 2016;9:242.

21. Lim R, Tripura R, Peto TJ, Sareth M, Sanann N, Davoeung C, et al. Drama as a community engagement strategy for malaria in rural Cambodia. Wellcome Open Res. 2017;2.

22. Pell C, Tripura R, Nguon C, Cheah $P$, Davoeung C, Heng C, et al. Mass anti-malarial administration in western Cambodia: a qualitative study of factors affecting coverage. Malar J. 2017;16:1-11.

23. Verschuere J, Decroo T, Lim D, Kindermans J-M, Nguon C, Huy R, et al. Local constraints to access appropriate malaria treatment in the context of parasite resistance in Cambodia: a qualitative study. Malar J. 2017;16:1-12.

24. Kunkel A, Nguon C, Iv S, Chhim S, Peov D, Kong P, et al. Choosing interventions to eliminate forest malaria: preliminary results of two operational research studies inside Cambodian forests. Malar J. $2021 ; 20: 51$.

25. Bannister-Tyrrell M, Gryseels C, Sokha S, Dara L, Sereiboth N, James N, et al. Forest goers and multidrug-resistant malaria in Cambodia: an ethnographic study. Am J Trop Med Hyg. 2019;100:1170-8.

26. Canavati SE, Kelly GC, Quintero CE, Vo TH, Tran LK, Ohrt C, et al. Risk factor assessment for clinical malaria among forest-goers in a pre-elimination setting in Phu Yen Province, Vietnam. Malar J. 2019;18:435.

27. WHO. Achieving and maintaining universal coverage with long-lasting insecticidal nets for malaria control. Geneva: World Health Organization. 2017.

https://www.who.int/malaria/publications/atoz/who_recommendation_coverage_llin/en/.

28. Bureau of Vector Borne Diseases. Guide to Malaria Elimination For Thailand's Local Administrative Organizations and the Health Network. Department of Disease Control, Ministry of Public Health, Thailand. 2019. http://malaria.ddc.moph.go.th/downloadfiles/Guide.

29. Than MM, Min M, Aung PL. The determinants of delayed diagnosis and treatment among malaria patients in Myanmar: a cross-sectional study. Open Pub Health J. 2019;12:78-85.

30. Sonkong K, Chaiklieng S, Neave P, Suggaravetsiri P. Factors affecting delay in seeking treatment among malaria patients along Thailand-Myanmar border in Tak Province, Thailand. Malar J. 2015;14:3.

\section{Figures}



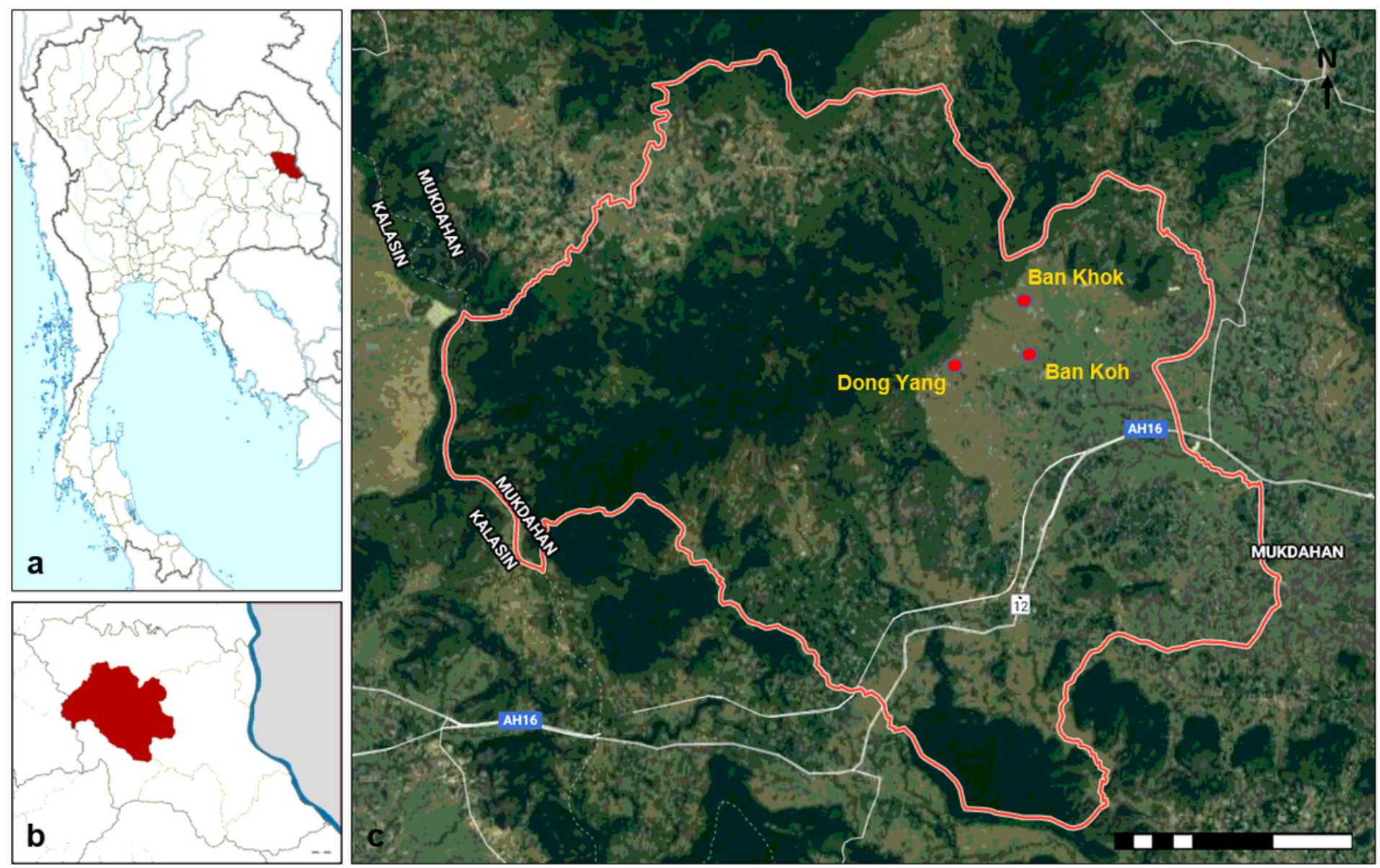

\section{Figure 1}

Map of study area. (a) Map of Thailand showing the location of Mukdahan Province (red). (b) Map of Mukdahan Province showing the location of Khamcha-i district (red). (c) The location of the three study villages within the Khamcha-i district. Note: The designations employed and the presentation of the material on this map do not imply the expression of any opinion whatsoever on the part of Research Square concerning the legal status of any country, territory, city or area or of its authorities, or concerning the delimitation of its frontiers or boundaries. This map has been provided by the authors. 